\title{
Cooling Module Device
}

National Cancer Institute

\section{Source}

National Cancer Institute. Cooling Module Device. NCI Thesaurus. Code C50319.

A device designed to regulate and lower the temperature of a heat generating device or system. 